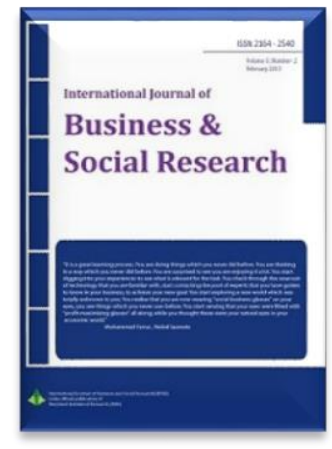

\title{
Are Crashes Good or Bad for NASCAR Sponsors?
}

\begin{abstract}
Sanghak Lee ${ }^{1}$
ABSTRACT

The purpose of the present research is to examine the influence of accidents (i.e., car crashes) on sponsorship effects (i.e., brand recall and attitude toward the brand) in NASCAR racing. An experiment was conducted with two types of experimental videos, one with a crash and the other with no crash. A total of 239 university students were divided into an experimental group and a control group. The research participants watched one of two types of videos and responded to a questionnaire. The results concluded that watching a crash increased brand recall, but it did not have an impact on attitude toward the brand. Another analysis revealed, however, experiment participants who watched a crash formed favorable attitude toward the sponsoring brand if their sensation seeking and sport fandom were high. These findings implies that an accident actually has positive impacts on sponsorship effects such as brand awareness and attitude toward the brand.
\end{abstract}

Keywords: Crash, NASCAR, sensation seeking, sponsorship, sport fandom.

JEL Codes: L83, M31, Z20, Z29.

Available Online: 14-04-2016.

This is an open access article under Creative Commons Attribution 4.0 License, 2016.

\section{$1.0 \quad$ INTRODUCTION}

Tragedy struck the ABC Supply 500 at Pocono Raceway on August 23, 2015 when an IndyCar Series driver named Justin Wilson died in an accident during the race. In lap 180, Sage Karam, who was leading in that lap, suddenly spun and hit the wall at turn one. A significant amount of debris from Karam's car went airborne, and one piece of that debris directly hit Wilson's helmet, causing a fatal head injury (Garrett, 2015). Wilson's death was the first fatality in an IndyCar Series race since Dan Wheldon's death during a race in 2011 and a tragic example of car accidents in auto races. While deaths are rare, there are many crashes and accidents during races. One statistic showed that each racing event in the 2015 NASCAR Sprint Cup Series saw an average of 8.2 cautions (Willis, 2015). Unsurprisingly, many racing reporters and commentators have often asserted that crashes are unavoidable and a part of auto racing. In addition to auto racing, there are many other relatively high-risk sports (e.g., the $X$ Games and MMA) that see comparatively high rates of accidents and injuries.

\footnotetext{
1 Assistant Professor, The School of Business, Korea Aerospace University, Gyeonggi-do, South Korea 10540. E-mail: sanghak.lee@kau.ac.kr, Tel:+82-2-300-0307
} 
Since almost all sports rely on the financial support of sponsors, sports teams and organizers are not the only entities concerned about accidents. Sponsors are also keenly interested in the issue, although their concern is mainly targeted toward the effects that accidents have on their brand image and awareness (Burton \& O'Reilly, 2012). For instance, an accident could cause negative feelings among spectators and audience members watching the scene, and this negative emotion could transfer from the event itself to the brand image. This concept is based on the image transfer model (Meenaghan, 2001). The native image caused by accidents could be especially critical for certain types of sponsors. Airline companies are a good example. For an airline engaged in a sponsorship deal, being associated with any type of accident could diminish the extent to which a viewer associates that airline with safety. With this in mind, Shaw (2011) suggested that airline companies should avoid sponsoring high-risk sports such as auto racing and extreme sports.

In addition, accidents can shorten the exposure time of sponsoring brands to spectators and audience members. A typical NASCAR race runs for about three hours, providing sponsors with adequate opportunities to expose their brands on the racing cars during the race. If a racing car is involved an accident and retires early, sponsors suffer an opportunity cost. As a result, sponsors can expect fewer sponsorship effects when accidents occur. Lee and Pedersen (2010) examined the relationship between sponsorship exposure frequency and sponsorship effects. They concluded that longer sponsorship exposure resulted in greater sponsorship effects in terms of brand awareness and attitudes toward the brand.

On the contrary, some believe that a crash in an auto racing event could actually have a positive impact on sponsorship effects. Lee (2010) found that NASCAR fans easily recalled a sponsor's brand after seeing a car crash during a NASCAR broadcast. He suspected that NASCAR fans had a better chance of remembering the brand because their focus was sharpened when witnessing a sensational crash. This conclusion is consistent with the information processing model, which takes into account exposure, attention, interpretation, and memory (Hawkins \& Mothersbaugh, 2013). Based on the model, stimuli that are more intense encourage viewers to pay closer attention, which results in them remembering communicated messages more easily. Therefore, watching a crash (i.e., receiving an intense stimulus) would compel sports fans to pay attention to the sponsor's brand.

Additional studies have concluded that people respond differently based on personal traits (e.g., sensation seeking) in violent/sensational situations. Leone and Arienzo (2000) found that sensation seeking subjects showed more favorable attitudes to highly arousing commercials. Another study concluded that different genders and personality traits influenced responses to violent advertisements for some sports (McDaniel, Lim, \& Mahan, 2007).

In summary, accidents are not avoidable in sports such as auto racing. Accordingly, sponsors are concerned and curious about the consequences that accidents will have on their sponsorship effects. Although there some presumptions have been expressed with respect to how accidents have influenced sponsorship effects, no study has examined this phenomenon. Therefore, the purpose of the study is to examine the influence of accidents (i.e., car crashes) on sponsorship effects in NASCAR racing.

To analyze crash effects on auto racing sponsorship, the researcher conducted an experiment with two types of experimental videos, one with a crash and the other with no crash. A total of 239 university students were divided into an experimental group and a control group. The research participants watched one of two types of videos and responded to a questionnaire. The results concluded that watching a crash increased brand recall, but it did not have an impact on attitude toward the brand. Another analysis revealed, however, experiment participants who watched a crash formed favorable attitude toward the sponsoring brand if their sensation seeking and sport fandom were high. A discussion of the findings and the research's business implications will be provided. 


\subsection{LITERATURE REVIEW}

Sponsorship has become one of the main marketing communication vehicles for many companies. Sponsorship spending worldwide was estimated at $\$ 60.2$ billion in 2016 ("As sponsorship borders fall," 2016). Therefore, many sport organizations, teams, scholars, and companies have shown considerable interest in how sponsorship effects are created and which variables influence sponsorship effects. Since sponsorship is regarded as a means of marketing communication, many sponsorship studies have examined how sponsorship activities influence sponsoring brand equity and sports fan purchasing decisions (e.g., Biscaia, Correia, Rosado, Ross, \& Maroco, 2013; Tsiotsou, Alexandris, \& Cornwell, 2014; Westberg \& Pope, 2014). In these studies, brand equity consisted of awareness, image, and attitude (Keller, 1993) and these components directly impacted consumer purchasing decisions. The hierarchy of effects model (Lavidge \& Steiner, 1961) stipulated that people went through a series of steps when making a buying decision. These steps consisted of awareness, knowledge, liking, preference (i.e., attitude), conviction, and purchase. Therefore, brand awareness, attitude toward the brand, and purchase intention were frequently measured as sponsorship effects in many sponsorship articles (e.g., Cianfrone \& Zhang, 2013; Mazodier \& Merunka, 2012).

In addition, many scholars developed theories to explore variables that influenced these sponsorship results. For example, Lee and Pedersen (2010) examined the relationship of the frequency of sponsorship exposure and attitude toward the brand using the mere exposure theory (Zajonc, 1968). Sport fandom (i.e., sport identification) was also included in many sponsorship articles. Sport fandom was defined as the involvement level that sports fans showed for a certain sport (Wann, 2002). For instance, if an individual's sport fandom level for soccer was high, that fan would show a lot of interest in soccer and enjoy playing or watching soccer games. It was demonstrated that sport fandom had a positive impact on sponsorship effects (Jensen, Bowman, Wang, \& Larson, 2012). In other words, when an avid sports fan enjoyed watching a sporting event, that individual remembered sponsoring brands more easily and formed more favorable attitudes toward the brands seen in the event compared to a casual (or non-) fan. Therefore, sport fandom was added as an independent variable or moderating variable in lots of sponsorship research (e.g., Hickman, 2015; Jensen, Walsh, Cobbs, \& Turner, 2015).

\subsection{AUTO RACING SPONSORSHIP}

Auto racing is one of the most popular sports in the world. Formula One (F1) racing is usually considered to be one of the top three mega sporting events with the Olympics and FIFA World Cup (Dolles \& Söderman, 2008). The World Rally Championship (WRC) is also very famous. In America, NASCAR and the IndyCar Series are loved by many racing fans. To design and manufacture racing cars and to operate teams, racing teams needed large budgets. For example, an F1 team's annual budget can easily exceed $\$ 300$ million, about 70 percent of which might come from sponsors; on average, a sponsor will spend $\$ 51.5$ million (Jensen \& Cobbs, 2014). In addition, the average annual revenue per NASCAR team has been estimated at $\$ 100$ million, with major sponsors spending up to $\$ 30$ million per year (Odland, 2012). Auto racing sponsorship revenue has rapidly increased since the 1970 s due to a ban on tobacco advertisements (Eckard, 1991). Many tobacco companies looked for alternative marketing communication channels, one of which was motor racing sponsorship became. Winston became the title sponsor for NASCAR racing for more than 30 years until 2003 (Fleischman \& Pearce, 1998).

As previously mentioned, auto racing contains a high risk of crashes and other types of accidents during racing events. However, no research has yet been conducted on how accidents influence sponsorship effects. Therefore, the purpose of this study is to investigate this relationship between crashes and sponsorship effects.

\subsection{SENSATION SEEKING IN COMMUNICATION}

There has been some research on the relationship between violent messages and communication effects, 
although no studies exist in this regard on sponsorship communications. In these studies, scholars paid attention to sensation seeking as a personal trait (e.g., McDaniel et al., 2007; Bustin, et al., 2015). Sensation seeking has been defined as one's level of pursuit of sensational stimuli and experiences (Zuckerman, 1971). High sensation seekers were willing to take risks for these experiences, and they enjoyed extreme sports and violent movies.

In communication studies, high sensation seekers paid greater attention and showed more favorable reactions to violent marketing messages than low sensation seekers (Bustin, et al., 2015; Lim, et al., 2013). Based on the previous research related to sensation seeking, a high sensation seeking racing fan would be expected to form more positive feelings toward a crash (i.e., violent and sensational stimulus). Therefore, this study has added sensation seeking as a construct, and it has examined sponsorship effects with respect to sensation seeking when people witness a crash. Therefore, the research constructs are as follows.

\subsection{RESEARCH CONSTRUCTS AND HYPOTHESES}

The purpose of the study was to find the relationship between watching a crash and the influence that event has on sponsorship effects. Therefore, crashes were selected as one of the main independent variables in the study. A crash was considered to be a sensational and violent event for sports fans (i.e., spectators and audience members). Based on Hawkins \& Mothersbaugh (2013), sensational stimuli compel viewers to pay more attention and remember messages more easily than non-sensational stimuli. Therefore, a sensational stimulus such as a crash in an auto race was expected to increase a viewer's memory retention with respect to a sponsoring brand name.

Brand recall was one of the components of brand awareness in brand equity. Brand awareness was deemed important because it was the first step in the hierarchy of effects model, which depicted a process that included awareness, knowledge, liking, preference (i.e., attitude), conviction, and purchase (Lavidge \& Steiner, 1961). In short, without remembering a brand, consumers had no chance to build brand attitudes or ultimately make a decision to purchase the brand. Brand awareness consisted of brand recall and brand recognition (Keller, 1993). While brand recognition was aided brand memory, brand recall was the ability to retrieve a brand without any prompting (i.e., unaided brand memory). As a result, brand recall was a higher level of memory retention than brand recognition. Many sponsorship studies have examined brand recall as a sponsorship effect, and it was determined that brand recall was influenced by sponsoring brand exposure (e.g., Herrmann, Corneille, Derbaix, Kacha, \& Walliser, 2014), sport fandom (Ko, Kim, Claussen, \& Kim, 2008), and other sponsorship activities. In the research, brand recall was also selected as one of the dependent variables, and it was impacted by watching a crash, sensation seeking, and sport fandom. As a result, the research hypothesis one is as follows.

$\mathrm{H} 1$. A crash will positively influence brand recall for a sponsoring brand.

Attitude was defined as the tendency to react to a certain object in either a favorable or unfavorable manner (Etzel, Walker, \& Stanton, 2007). Attitude toward a brand was the overall assessment of a certain brand (Keller, 1993), and it was also one of the steps in the aforementioned hierarchy of effects model (Lavidge \& Steiner, 1961). Consumers and sports fans formed an intention to make a purchase and decided to carry out that purchase after forming a favorable attitude toward the brand. Therefore, a significant amount of sponsorship literature included attitude toward the brand and regarded it as one of the main sponsorship effects. Attitude toward the brand was influenced by many variables, including sport fandom (Ko, et al., 2008), exposure frequency (Lee \& Pedersen, 2011), image congruence between an endorser and a sponsoring brand (Mazodier \& Merunka, 2012), and additional sports fan demographic variables such as gender (McDaniel \& Kinney, 1998). In addition, sensation seeking affected communication effects in sensational and violent marketing communications. Therefore, it was concluded that attitude toward the brand would be influenced by sensation seeking and sport fandom. Therefore, the research hypothesis two is suggested as follows.

H2. A crash will positively influence attitude toward the brand for a sponsoring brand. 
Sensation seeking has been defined as a personal characteristic that compels an individual to desire novelty, complexity, and intensity (Stephenson, Velez, Chalela, Ramirez, \& Hoyle, 2007). In other words, people have different personal traits, and some people are more likely to pursue a sensational experience even when that experience might entail risk. In communications, it was found that consumers deemed to be high sensation seekers tended to form favorable attitudes toward sensational and violent messages (Lim, et al., 2013). In that research, high sensation seekers were assumed to pay greater attention and create more favorable attitudes toward a sponsoring brand when a sensational event such as a car crash occurred.

Sport fandom (i.e., sport identification) has been defined as a sports fan's involvement level for a specific sport (Wann, 2002). Therefore, it was determined that sports fans measuring high on the sport fandom scale most likely enjoyed watching and following the sports. In addition, it was concluded that avid sports fans were also more favorable to a sponsoring brand because they recognized that sponsors were supporting the sport that they had strong feelings toward (Madrigal, 2000). In other words, the fans felt camaraderie with the sponsoring company. As a result, sport fandom was thought to have a positive impact on sponsorship effects such as brand recall and attitudes toward a brand. Based on the literature review, the third and fourth research hypotheses are as follows.

H3. Sensation seeking and sport fandom will have a positive impact on brand recall when the sponsoring brand is involved in a crash.

H4. Sensation seeking and sport fandom will have a positive impact on attitude toward the brand when the sponsoring brand is involved in a crash.

Based on the research hypotheses, a research framework was developed. This framework is illustrated in Figure 1.

\section{Figure 1: Research framework}

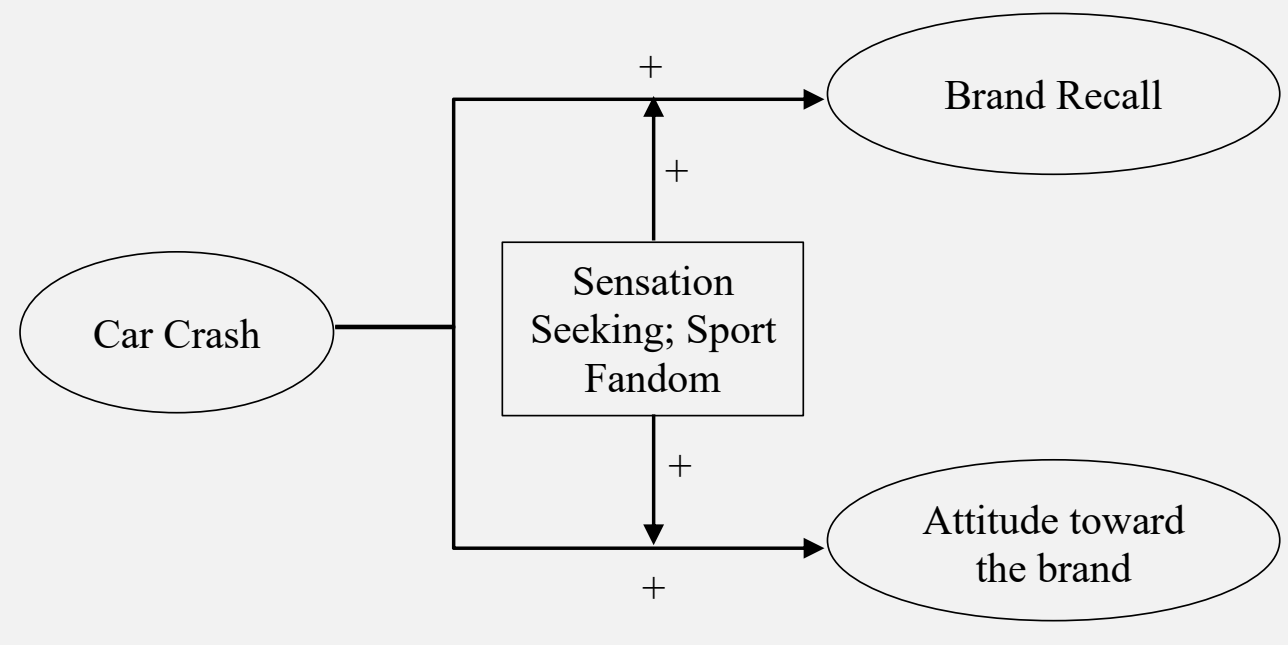

\subsection{METHOD}

To examine the different sponsorship effects derived from a race car crash, an experiment was conducted. Two types of 10-minute videos were created for experimental manipulation. The experimental videos were edited from a NASCAR race (i.e., the Coca-Cola 600) held at the Charlotte Motor Speedway. This race was chosen for the experiment due to the occurrence of accidents and crashes. In the race, there were a total of 14 yellow flags (i.e., accidents or crashes). Most yellow flags 
were caused by minor accidents without a crash, e.g., debris on the race track. Therefore, a scene was selected that included a crash. During the crash, the sponsor's brand could be seen. This crash occurred on lap 240 (out of total 400 laps). The \#56 race car driven by Martin Truex Jr. was involved in the accident, and the logo of the sponsor, NAPA, was clearly shown for a couple of seconds (see Figure 2). The 10minute highlight videos were edited from the three hour long original race, and these highlight videos ended at lap 394 in order to hide the results of the race. The only difference between the two videos was that one included the crash and the other did not. In other words, the video for the experimental group contained a three-second crash scene in the middle of the 10-minute highlight, while the video for the control group contained no crash scenes in the same highlight video.

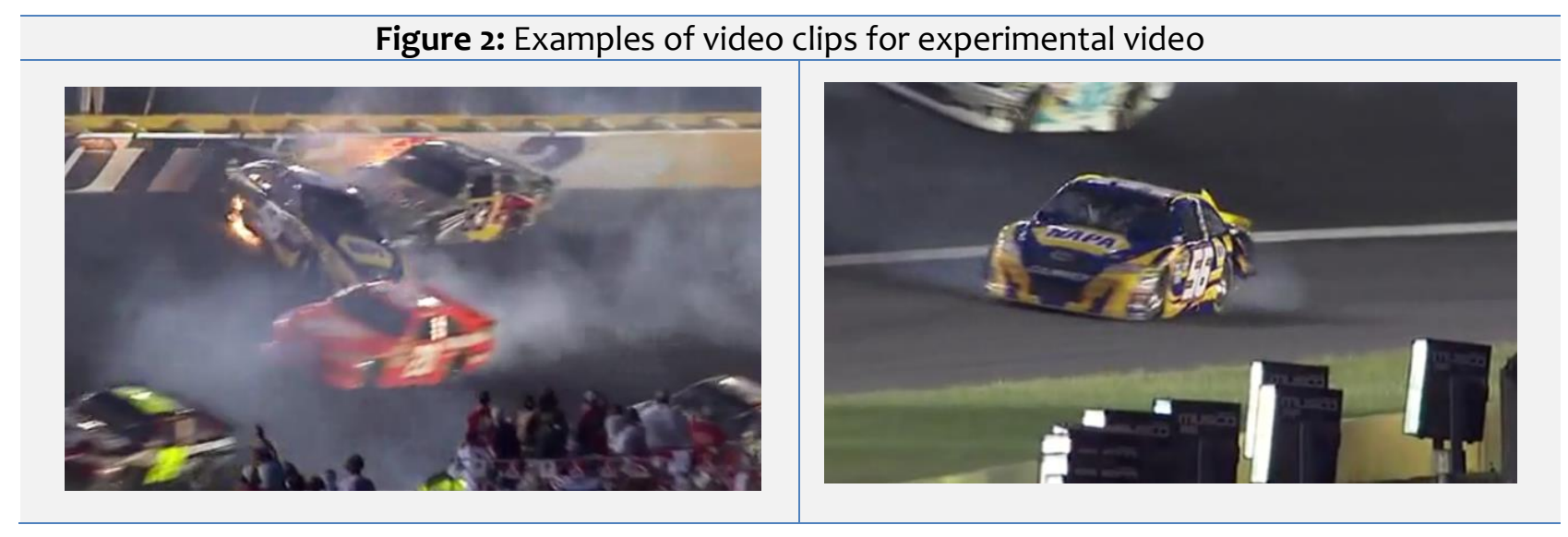

The experiment was conducted among university students located in the South Central region of the United States. The 239 research participants were randomly divided into either an experimental group (with the crash) or a control group (without the crash). The majority $(n=129)$ of the participants were assigned to the experimental group while the remaining 110 participants were assigned to the control group. The research participants in each group watched the experimental video for 10 minutes in separate locations. After watching the experimental videos, the participants were asked to respond to a questionnaire that measured the research variables. The questionnaire consisted of five parts. The first two parts explored the independent variables (i.e., sport fandom and sensation seeking), and next two parts measured the dependent variables (i.e., brand recall and attitude toward the brand). The last part of the questionnaire was designed to measure demographic variables of the research participants. These variables included age, gender, and ethnic group.

Several statistical methods were used to analyze the data. Descriptive statistics were used to determine the participants' demographic backgrounds. An explorative factor analysis and reliability test were also conducted to check the validity and reliability of the research scales. Lastly, a cross tabulation analysis, $t$ test, and two-way ANOVA was used to test the research hypotheses. All statistical analyses were calculated using SPSS.

\subsection{RESULTS AND DISCUSSIONS}

The characteristics of the research participants were as follows. There were 93 (38.9\%) male participants and $146(61.1 \%)$ female participants. The mean age of the participants was 22.82; the youngest was 19 and the oldest was 51. In terms of ethnic group, 132 (52.2\%) participants were Caucasian, 72 (30.1\%) participants were African American, and 35 (17.7\%) participants fell in the 'others' category. Table 1 shows a detailed breakdown of the demographics of the research participants. 


\begin{tabular}{lrr}
\hline \multicolumn{2}{c}{ Table 1: Sample description } \\
\hline Variables & Frequency & \\
\hline Gender & & Percentage \\
Male & 93 & 38.9 \\
Female & 146 & 61.1 \\
Age & & \\
$19-20$ & 104 & 43.5 \\
$22-25$ & 102 & 42.7 \\
$25-29$ & 22 & 9.2 \\
30 or above & 11 & 4.6 \\
Race & & \\
White & 132 & 55.2 \\
African American & 72 & 30.1 \\
Hispanic/Latino & 15 & 6.3 \\
Asian & 11 & 4.6 \\
Others & 9 & 3.8 \\
Do you have any favorite NASCAR drivers? & & \\
Yes & 61 & 25.5 \\
No & 178 & 74.5 \\
\hline
\end{tabular}

A manipulation check was then conducted for the experimental videos. 93.8 percent of the research participants in the experimental group (with the crash) responded that they watched the crash in the video, while 97.2 percent of research participants in the control group (without the crash) reported that they did not watch a crash in the video. Therefore, it was deemed that the experimental videos for both groups were manipulated properly (see Table 2).

\begin{tabular}{lrr}
\hline & Table 2: Manipulation Check & \\
\hline Variables & Frequency & Percentage \\
\hline Experimental Group & & \\
Watched crash & 121 & 93.8 \\
Did not watch crash & 8 & 6.2 \\
Control Group & & \\
Watched crash & 3 & 2.8 \\
Did not watch crash & 106 & 97.2 \\
\hline
\end{tabular}

The validity and reliability of the research scales were tested. First, the scales were borrowed from previous studies in which tests were carried out on the validity and reliability. Second, an exploratory factor analysis was conducted to test the validity of the scales. Sport fandom had five items and was converged into one factor; its factor loading was $80.66 \%$. Sensation seeking had eight items, and attitude toward the brands had seven items; they had $77.80 \%$ and $75.53 \%$ factor loadings, respectively. These results showed that the validities of all three scales were relatively high. The reliability of the research scales was also tested. Cronbach's $\alpha$ of sport fandom, sensation seeking, and attitude toward the brand were $.94, .78$, and .94 , respectively. Therefore, these three research scales were deemed reliable. The other research variable, brand recall, was not tested for validity or reliability because this variable was measured by only one question: whether participants could retrieve the experimental brand, NAPA, or not. The detailed survey items and validity and reliability test results are shown in Table 3.

Table 3: Survey Items, Validity, and Reliability of Scales

Sport Fandom (Wann, 2002)

I consider myself to be a NASCAR fan.

My friends see me as a NASCAR fan.

I believe that following NASCAR is the most enjoyable form of entertainment.

My life would be less enjoyable if I were not allowed to follow NASCAR.

Being a NASCAR fan is very important to me

Mean $=1.90(1.36)$; Range $=1-7 ;$ Factor Loading $=80.66 \%$; Cronbach's $\alpha=.94$ 


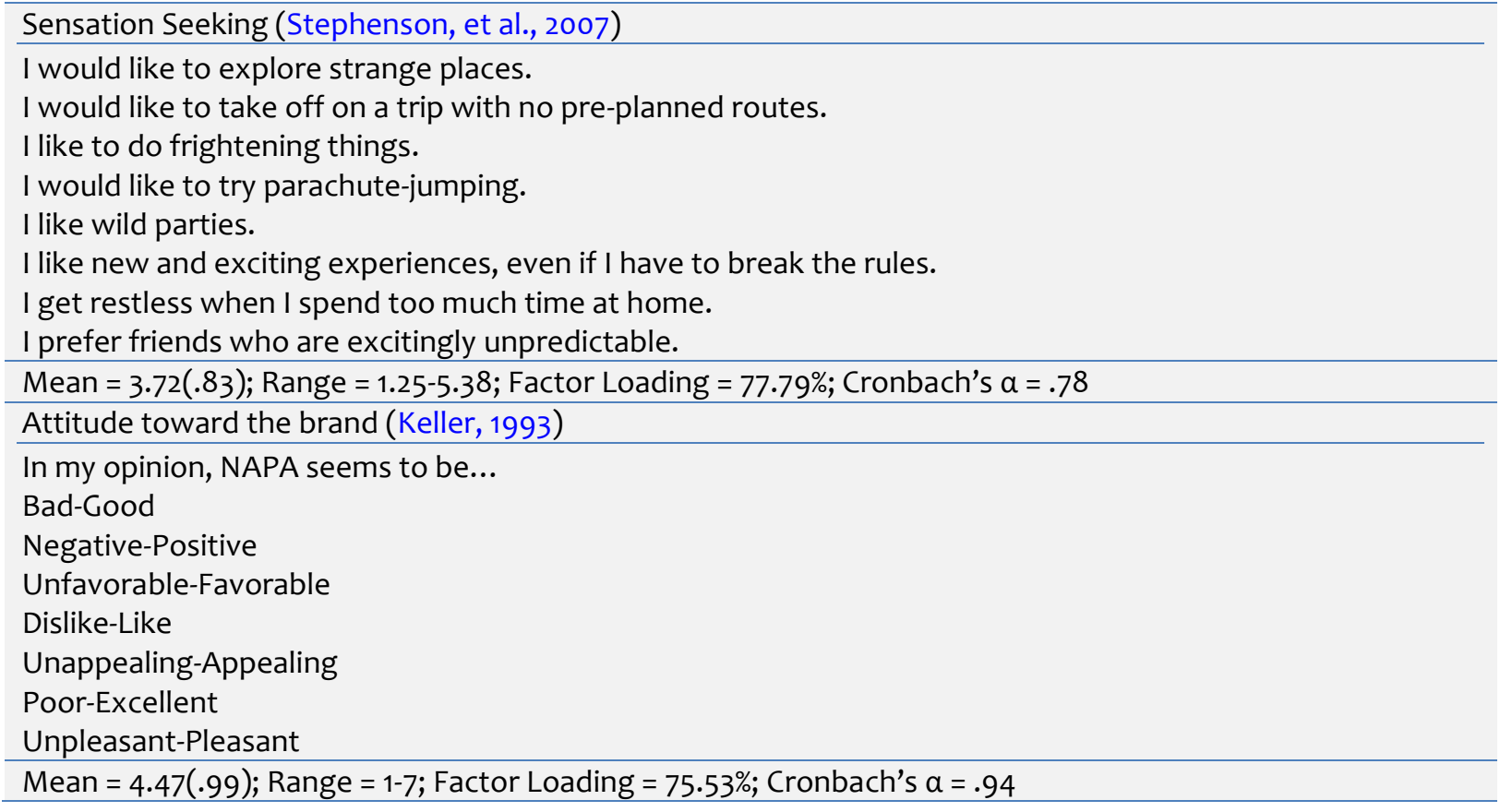

After testing the validity and reliability of the research scales, the main analyses were conducted to test the research hypotheses. The first hypothesis assumed that the existence of a crash influenced brand recall. To compare brand recall between participants in the experimental and control groups (i.e., those who had and had not watched the crash), a cross-tabulation analysis was performed. In the experimental group, 66 (51.2\%) participants correctly recalled the sponsoring brand, NAPA. In contrast, only 27 (24.5\%) participants in the control group remembered the sponsoring brand. An additional $X^{2}$ analysis gave $X^{2}=$ 17.70, $d f=1, \alpha<.001$, meaning that the brand recall frequency difference between the experimental and control groups was statistically significant (see Table 4). Therefore, hypothesis one was accepted.

\begin{tabular}{|c|c|c|c|c|c|}
\hline \multicolumn{6}{|c|}{ Table 4: Cross tabulation analyses: Recall by experimental and control groups } \\
\hline \multirow{2}{*}{ Group } & \multicolumn{3}{|c|}{ Recall Yes } & \multirow{2}{*}{$\begin{array}{r}\text { Recall No } \\
\text { Percentage }\end{array}$} & \multirow{2}{*}{ Total } \\
\hline & Frequency & Percentage & Frequency & & \\
\hline Experimental & 66 & 51.2 & 63 & 48.8 & 129 \\
\hline Control & 27 & 24.5 & 83 & $75 \cdot 5$ & 110 \\
\hline
\end{tabular}

The second hypothesis expected that a crash would affect attitude toward the brand. To test the hypothesis, the mean scores of attitude toward the brand were compared between the two groups by conducting a t-test for independent samples. The means of the experimental and control groups were 4.47 (1.02) and $4.46(.96)$, respectively. A t-test resulted in $F=.89, \alpha=.34$. This indicates that the mean difference between the two groups was statistically insignificant (see Table 5). Therefore, hypothesis two was rejected.

\begin{tabular}{lcr}
\hline Table 5: T-Test: Means of attitude toward the brand by experimental and control groups \\
\hline Group & Attitude & T-Test \\
\hline Experimental & $4.47(1.02)$ & $F=.89, \alpha=.35$ \\
Control & $4.46(.96)$ & $t=-.09, d f=237$ \\
\hline
\end{tabular}

Next, the third hypothesis was tested to see if sensation seeking and sport fandom influenced brand recall. To test the hypothesis, data were selected only from the experimental group in which the participants watched the crash. First, the participants in the experimental group were divided into two (high and low) sensation seeking groups and two (high and low) sport fandom groups $(2 \times 2)$ based on their sensation seeking and sport fandom scores. Second, another cross-tabulation analysis was conducted to compare the frequency difference of brand recall among the groups. The results indicated 
that brand recall frequency by sensation seeking and sport fandom groups were not significantly different from one another. The $X^{2}$ analysis also showed that $X^{2}=.073, d f=1, \alpha=.79$, meaning that the frequency difference among the groups was statistically insignificant (see Table 6 ). Therefore, hypothesis three was rejected.

\begin{tabular}{lrrrrr}
\hline \multicolumn{5}{c}{ Table 6: Cross tabulation analyses: Recall by Sport Fandom (SF) and Sensation Seeking (SS) Groups } \\
\cline { 2 - 5 } Group & Rrequency & Pecall Yes & Recall No & Total \\
\cline { 2 - 5 } & 33 & 50.0 & 33 & 50.0 & 66 \\
SF High & 33 & 52.4 & 30 & 47.6 & 63 \\
SF Low & 33 & 54.1 & 28 & 45.9 & 61 \\
Pearson $X^{2}=.07, d f=1, \alpha=.787$ & & 48.5 & 35 & 51.5 & 68 \\
SS High & 33 & & & & \\
SS Low & & & & & \\
Pearson $X^{2}=.399, d f=1, \alpha<.582$ & &
\end{tabular}

Lastly, the fourth hypothesis was analyzed. The last hypothesis assumed that sensation seeking and sport fandom would affect attitude toward the sponsoring brand. As in the previous hypothesis test, data collected from the experimental group were included in the analysis, and the research participants were also divided into four groups by their sensation seeking (high and low) and sport fandom (high and low) levels $(2 \times 2)$. A two-way ANOVA was conducted to compare the mean difference of attitude toward the brand, NAPA, among the groups. The results showed that the high sensation seeking and high sport fandom group scored the highest attitude toward the brand $(M=4.88)$, while the low sensation seeking and low sport fandom group scored the lowest attitude toward the brand $(M=4.17)$. The two-way ANOVA revealed that the main effects of sensation seeking were $F=4.10, \alpha=.045$, and the other main effects of sport fandom were also $F=4.10, \alpha=.045$. On the contrary, the interaction effect between sensation seeking and sport fandom was $F=.10, \alpha=.586$ (see Table 7). These results indicated that sensation seeking and sport fandom independently and positively affected attitude toward the sponsoring brand, while there was no interaction effects between the independent variables. As a result, hypothesis four was accepted.

Table 7: Two-way ANOVA: Means of Attitude toward the Brand by Sport Fandom (SF) and Sensation Seeking (SS) Groups

\begin{tabular}{lrr} 
Group & SF High & SF Low \\
\hline SS High & $4.88(1.08)$ & $4.43(.97)$ \\
SS Low & $4.43(.98)$ & $4.17(.96)$ \\
\hline
\end{tabular}

\begin{tabular}{lrrrrr}
\hline Source & SS & $d f$ & $M S$ & $F$ & $p$ \\
\hline Sensation Seeking (SS) & 4.07 & 1 & 4.07 & 4.10 & .045 \\
Sport Fandom (SF) & 4.07 & 1 & 4.07 & 4.10 & .045 \\
SS $\times$ SF & .30 & 1 & .30 & .30 & .586 \\
error & 124.02 & 125 & .99 & & \\
\hline Note: SS = sum of squares; MS = mean square. & & & & \\
\hline
\end{tabular}

The purpose of this research was to examine whether or not different sponsorship effects existed in the event of a race car crash during an auto race. In addition, the study also analyzed whether or not sensation seeking and sport fandom influenced sponsorship effects when a crash occurred. Hypothesis one expected that a crash would affect sponsoring brand recall, and this hypothesis was accepted. In other words, the research participants watching a crash in the experimental group more easily retrieved the sponsoring brand, NAPA. This phenomenon fits in line with the information processing model (Hawkins \& Mothersbaugh, 2013). The crash made the moment more sensational, so viewers paid more attention to the crash and remembered the brand involved in the crash more easily. The second hypothesis dealt with the relationship between the crash and attitude toward the brand. This hypothesis was rejected, meaning that watching a crash did not influence attitude toward the brand either negatively or positively. Thus, watching a crash during a race event was neither positive nor negative, but rather a neutral stimulus to sponsoring brand attitude from the perspective of sponsors. 
Hypothesis three presumed that sensation seeking and sport fandom would affect sponsoring brand recall. The third hypothesis was rejected, and it was concluded that racing fans' sensation seeking and sport fandom levels were not able to influence brand recall. The last hypothesis surmised that sensation seeking and sport fandom affected the attitude toward the sponsoring brand, and this hypothesis was accepted. It was concluded that that people who looked for sensational events and who were avid NASCAR fans felt more favorable feelings toward the sponsoring brand when they watched a crash. This conclusion is similar to prior study. Bustin, et al., (2015) concluded that sensation seeking positively influence subliminal advertising effects. The results of hypotheses three and four suggest that brand recall is mainly influenced by only sensation (i.e., a crash), while brand attitude is mostly affected by a sports fan's psychologic variables (i.e., sensation seeking and sport fandom).

In conclusion, a crash during a racing event influenced sponsorship effects, and the main findings were as follows. First, the crash helped racing viewers to remember the sponsoring brand more easily. Second, race fans' sensation seeking and sport fandom levels positively influenced their attitude toward the sponsoring brand. Third, no negative sponsorship impacts were observed after the viewers witnessed the crash. As a result, it could be argued that crashes served to increase sponsorship effects (i.e., brand recall and attitude toward the brand) without harming a sponsor's brand image.

Based on the research conclusions, several business implications can be suggested. First, race organizers, teams, and sponsors should distinguish controllable and uncontrollable factors in attempting to enhance sponsorship effects. Since accidents can be considered to be uncontrollable factors, sponsors and other sponsorship stakeholders should pay attention to controllable factors when they choose sponsorship deals. First, accidents are not a negative factor but a neutral or positive factor in terms of brand recall and brand attitude. As such, prospective sponsors need not refrain from sponsoring an auto racing team or other extreme sport-related team or individual. In fact, it might be beneficial for potential sponsors to search for a racing team or driver with an aggressive racing style. For example, an energy drink brand, Red Bull, has achieved great business success through various sponsorship with exciting sports such as F1, NASCAR, and other extreme sports. Red Bull became the most famous energy drink brand and sold more than five billion cans a year (Indja, 2013).

Second, prospective sponsors should research the fan base of racing teams and drivers. Since sensation seeking and sport fandom enhanced attitude toward the brand, sponsors would do well to find a racing team or driver whose fan base had high sensation seeking and high sport fandom levels. In general, young male sports fans score relatively high in sensation seeking (McDaniel \& Zuckerman, 2003), so sponsors could look for teams that attracted more young male fans. In terms of sport fandom, sponsors would do well to search for racing teams and drivers that attract avid fans. This attraction is often related to team's winning and historical tradition (Sutton, William, McDonald, Mine, Cimperman, 1997). Therefore, sponsors have most likely benefited from engaging in a sponsorship contact with teams and drivers having lots of legacy and trophies. Sponsors would also benefit from fostering team's fans in an effort to transform them from casual to avid fans. Driver autograph events or other pre-race fan-oriented experiences are simple but effective ways to engage fans more effectively.

This study had some limitations. First, the experiment was only based on a NASCAR video, while other types of racing (e.g., F1, IndyCar Series) or sports were not tested. Second, only one level of sensational stimuli (i.e., a race car crash) was manipulated in the experiment. Different levels of stimuli, either milder or more severe, could induce different results. Therefore, future research should examine sponsorship effects according to different levels of sensational/violent stimuli.

\section{REFERENCES}

As sponsorship borders fall, spending rises. (2016, January 5). IEG Sponsorship Report. Retrieved from http://www.sponsorship.com

Biscaia, R., Correia, A., Rosado, A. F., Ross, S. D., \& Maroco, J. (2013). Sport sponsorship: The relationship 
between team loyalty, sponsorship awareness, attitude toward the sponsor, and purchase intentions. Journal of Sport Management, 27(4), 288-302.

Burton, R., \& O'Reilly, N. (2012, December 10). How fan, sponsor reactions factor into team decisions. Street \& Smith's SportsBusiness Journal, 15(34), 35.

Bustin, G. M., Jones, D. N., Hansenne, M., \& Quoidbach, J. (2015). Who does Red Bull give wings to? Sensation seeking moderates sensitivity to subliminal advertisement. Frontiers in Psychology, 6. 1-6.

Cianfrone, B. A., \& Zhang, J. (2013). The impact of gamer motives, consumption, and in-game advertising effectiveness: A case study of football sport video games. International Journal of Sport Communication, 6, 325-347.

Dolles, H., \& Söderman, S. (2008). Mega-sporting events in Asia-Impacts on society, business and management: An introduction. Asian Business \& Management, 7(2), 147-162.

Eckard, E. W., Jr. (1991). Competition and the cigarette TV advertising ban. Economic Inquiry, 29, 119-133.

Etzel, M. J., Walker, B. J., \& Stanton, W. J. (2007) Marketing (14th ed.). Boston: McGraw-Hill.

Fleischman, B., \& Pearce A. (1998). Inside sport NASCAR racing. Canton, MI: Visible Ink.

Garrett, J. (2015, August 26). Driver killed in IndyCar wreck was a student of crashes. The New York Times, pp. B9, B13.

Hawkins, D. I., \& Mothersbaugh, D. L. (2013). Consumer behavior: Building marketing strategy (12th ed.), New York: McGraw-Hill.

Herrmann, J. L., Corneille, O., Derbaix, C., Kacha, M., \& Walliser, B. (2014). Implicit sponsorship effects for a prominent brand. European Journal of Marketing, 48(3/4), 785-804.

Hickman, T. M. (2015). The impact of fan identification, purchase intentions, and sponsorship awareness on sponsors' share of wallet. Sport Marketing Quarterly, 24, 170-182.

Indja, S. (2013). How Red Bull reinvented sports marketing. The Sports Business Exchange. Retrieved from http://www.thesportsbusinessexchange.com/2013/11/how-red-bull-reinvented-sportsmarketing/

Jensen, J. A., \& Cobbs, J. (2014). Analyzing return-on-investment in sponsorship: Modeling brand exposure, price and ROI in Formula One racing. Journal of Advertising Research, 54(4), 435-447.

Jensen, J. A., Walsh, P., Cobbs, J., \& Turner, B. A. (2015). The effects of second screen use on sponsor brand awareness: a dual coding theory perspective. Journal of Consumer Marketing, 32(2), 71-84.

Jensen, R., Bowman, N., Wang, Y., \& Larson, B. (2012). New league, new market and new sponsorship: an exploratory study of attitudes towards shirt sponsorship in Major League Soccer. Soccer \& Society, 13(4), 536-554.

Keller, K. L. (1993). Conceptualizing, measuring, and managing customer-based brand equity. Journal of Marketing, 57, 1-22.

Ko, Y. J., Kim, K., Claussen, C. L., \& Kim, T. H. (2008). The effects of sport involvement, sponsor awareness and corporate image on intention to purchase sponsors' products. International Journal of Sports Marketing \& Sponsorship, 9(2), 79.

Lavidge, R. J., \& Steiner, G. A. (1961). A model for predictive measurements of advertising effectiveness. Journal of Marketing, 25(6), 59-62.

Lee, S. H. (2010). Influence of brand exposure frequency and sport involvement on sport sponsorship effects: An examination of mere exposure (Unpublished doctoral dissertation). Indiana University, Bloomington, IN.

Lee, S. H., \& Pedersen, P. M. (2010). The influence of brand exposure frequency and brand familiarity on sport sponsorship effects: An examination of mere exposure. International Journal of Sports Sciences and Physical Education, 1(1), 15-20.

Lee, S. H., \& Pedersen, P. M. (2011). Measuring sponsorship effects in intercollegiate sport: An examination of Division I basketball. Journal of Sponsorship, 4(4), 391-401.

Leone, C., \& D'arienzo, J. (2000). Sensation-seeking and differentially arousing television commercials. The Journal of Social Psychology, 140(6), 710-720.

Lim, C., Lee, W. Y., \& Pedersen, P. M. (2013). Investigating the moderating role of sport service type and personality on audiences' emotional responses to hedonic vs. cognitive advertisements. Journal of Global Scholars of Marketing Science, 23(1), 55-71.

Madrigal, R. (2000). The influence of social alliances with sports teams on intentions to purchase corporate sponsors' products. Journal of Advertising, 29(4), $13-24$. 
Mazodier, M., \& Merunka, D. (2012). Achieving brand loyalty through sponsorship: the role of fit and selfcongruity. Journal of the Academy of Marketing Science, 40(6), 807-820.

McDaniel, S. R., \& Kinney, L. (1998). The implications of recency and gender effects in consumer response to ambush marketing. Psychology \& Marketing, 15(4), 385-403.

McDaniel, S. R., Lim, C., \& Mahan, J. E. (2007). The role of gender and personality traits in response to ads using violent images to promote consumption of sports entertainment. Journal of Business Research, 60(6), 606-612.

McDaniel, S. R., \& Zuckerman, M. (2003). The relationship of impulsive sensation seeking and gender to interest and participation in gambling activities. Personality and Individual Differences, 35(6), 13851400.

Meenaghan, T. (2001). Understanding sponsorship effects. Psychology \& Marketing, 18(2), 95-122.

Odland, S. (2012, February 27). NASCAR's back! Forbes. Retrieved from http://www.forbes.com/sites/steveodland/2012/02/27/nascars-back/\#2737b6e71c1d

Shaw, S. (2011). Airline marketing and management. Surrey, UK: Ashgate.

Stephenson, M. T., Velez, L. F., Chalela, P., Ramirez, A., \& Hoyle, R. H. (2007). The reliability and validity of the Brief Sensation Seeking Scale (BSSS-8) with young adult Latino workers: Implications for tobacco and alcohol disparity research. Addiction, 102(s2), 79-91.

Sutton, W. A., McDonald, M. A., Mime, G. R., \& Cimperman, J. (1997). Creating and fostering fan identification in professional sports. Sport Marketing Quarterly, 6(1), 15-22.

Tsiotsou, R. H., Alexandris, K., \& Cornwell, T. B. (2014). Using evaluative conditioning to explain corporate co-branding in the context of sport sponsorship. International Journal of Advertising: The Review of Marketing Communications, 33(2), 295-327.

Wann, D. L. (2002). Preliminary validation of a measure for assessing identification as a sport fan: The sport fandom questionnaire. International Journal of Sport Management, 3, 103-115.

Westberg, K., \& Pope, N. (2014). Building brand equity with cause-related marketing: A comparison with sponsorship and sales promotion. Journal of Marketing Communications, 20(6), 419-437.

Willis, K. (2015, December 5). Rubbin's Racin': A look back where they wrecked, and how often, in 2015. The Daytona Beach News-Journal. Retrieved from http://www.newsjournalonline.com/article/20151205/SPORTS/151209770

Zuckerman, M. (1971). Dimensions of sensation seeking. Journal of Consulting and Clinical Psychology, 36, 45-52.

Zajonc, R. B. (1968). Attitudinal effects of mere exposure. Journal of Personality and Social Psychology, 9(2), 1-27. 